\title{
Healing Effect of the Extract of Kombucha in Male Wistar Rats
}

\author{
Manuel Rosales-Cortés*, Esther Albarrán-Rodríguez, Guillermo Nolasco-Rodríguez, \\ David Avíla-Figueroa, Raúl Leonel De Cervantes-Mireles, Rubén Rosales-Ramírez, \\ Dora Manuela García-Carrasco \\ División de Ciencias Veterinarias, Centro Universitario de Ciencias Biológicas Agropecuarias, Universidad de \\ Guadalajara, Guadalajara, Mexico \\ Email: mrosales@cucba.udg.mx
}

Received 13 March 2015; accepted 1 April 2015; published 2 April 2015

Copyright (C) 2015 by authors and Scientific Research Publishing Inc.

This work is licensed under the Creative Commons Attribution International License (CC BY). http://creativecommons.org/licenses/by/4.0/ (c) (i) Open Access

\begin{abstract}
In order to assess the impact of the early and late tissue repair of Kombucha extract on incised wounds in animal models, 24 Wistar male rats were used and divided into three groups: one of the groups received a topical cure on the wound with Brosin, and the other received the Kombucha extract. The third group did not receive any treatment, working as a control group. The objective was to evaluate and compare the Kombucha extract with a commercial healing product. Each one of the animals took a $1 \mathrm{~cm}$ wound in depth and length at a femur level on a side of the left thigh. The healing process was evaluated on an early and late phase by performing a morphometric and morphological analysis under the assumption of a faster recovery with the use of Kombucha. The results showed that there was a poor recovery in the control group. On the other hand, the other two groups, Brosin and Kombucha, were similar, with little inflammation and a high cell proliferation and migration along with basal array pulls of elastin and collagen which served for angiogenesis, repair and renovation of the new tissue.
\end{abstract}

\section{Keywords}

Healing, Kombucha, Repair and Tissue Regeneration

\section{Introduction}

When the skin or muscles are injured, a complex process of healing begins. It triggers a series of cellular actions combined with humoral and biochemical events that mark three stages: inflammatory or early, fibro-proliferative

*Corresponding author.

How to cite this paper: Rosales-Cortés, M., Albarrán-Rodríguez, E., Nolasco-Rodríguez, G., Avíla-Figueroa, D., De CervantesMireles, R.L., Rosales-Ramírez, R. and García-Carrasco, D.M. (2015) Healing Effect of the Extract of Kombucha in Male Wistar Rats. Open Journal of Veterinary Medicine, 5, 80-88. http://dx.doi.org/10.4236/ojvm.2015.54011 
or intermediate phase, and remodeling which is the late phase. The first starts at the time of the injury, and for the next 48 hours. After the fifth day, late-stage changes can be seen. Such changes can vary depending on the type of lesion and the tissues involved [1].

The reconstruction of tissue requires lots of energy and protein synthesis, so the metabolism increases locally, flushing the area. As a result of the inflammatory process in the damaged tissue, there is attraction of monocyte chemotactic and macrophages, which are necessary to produce growth factors as well as platelets which are the blood clot forming [2] [3].

Then, the formation of the basal matrix starts. This matrix is formed with elastin and collagen, and serves as a bridge for proliferation and cell migration where the increases in neutrophils, fibrocytes, fibroblasts, macrophages and other cells in the process of inflammation are present. At the same time, angiogenesis takes place, which is the compaction of the tissue to get rid of the crust and start with new tissue remodeling [1]-[4].

Ferments from which the Kombucha tea is obtained are an organic and symbiotic growth from yeasts and beneficial bacteria that form a zooglea. Its composition is controversial since it is not an organism as fungi or algae maybe; it has part of both and has a pH of 2.8 - 4 at the temperature of $26^{\circ} \mathrm{C}$ [5].

It was observed that it stimulates the immune system to strengthen cell membranes against the attack of pests and candidiasis by activity of butyric acid and glucuronic acid [6] [7].

The production of glucuronic acid at a rate of $0.38 \mathrm{~g} / 100 \mathrm{ml}$ on the $14^{\text {th }}$ day of fermentation helps stabilize the metabolism and detoxify it. When it is combined with the endogenous or exogenous substances that act as toxins and waste, it prevents the body from absorbing such substances. Therefore, they are eliminated by the body's excretory system helping to lower blood pressure, prevent atherosclerosis and decrease cholesterol. The conjugation of the glucuronyl-transferase stimulates the glucuronidation as a result increasing the body's defenses as in vigor and generalized well-being [6] [7].

Also, the Kombucha has antibacterial and antimicrobial activity by the presence of usnic acid of $0.65 \mathrm{~g} / 100 \mathrm{ml}$ and acetic acid of $1.60 \mathrm{~g} / 100 \mathrm{ml}$, present in the fermentation of the $14^{\text {th }}$ day, mainly attacking Estaphilococcusaureus, Shigella sonnei, E. coli, Aeromonashidrophila, Yeseniaenterolitica, Pseudomonas aeruginosa, Enterobacter cloacae, Estaphilococcus epidermis, Campylobacter jejuni, Salmonella enteritidis, Salmonella typhimurium, Bacillus cereus, Helicobacter pylori and Listeria monocytogenes [8]-[10].

A lot of drugs and drugs patent with antibiotic and anti-inflammatory are currently available in the market. One of the most common contains neomycin sulfate tetracycline hydrochloride, prednisolone acetate and vitamin A, and offers large effects of repair in the healing process by inhibiting the inflammation and possible contamination; however, this type of medication has a high cost or side effects as containing corticosteroids [11].

Therefore, it is necessary to find and utilize natural and low-cost alternative treatments which are practical and promote effective damaged tissue repair without collateral, economic effects that inhibit inflammation and pollution as it is the case of Kombucha that studies extract prior proved to meet all these qualities [12].

\section{Materials and Methods}

This work was carried out in the facilities of the Laboratory of Morphophysiology of the Department of Veterinary Medicine and Animal Production of the University of Guadalajara, Campus of Biological Sciences and Agropecuary.

\section{Experimental Design}

24 young, male Wistar rats were used of $250 \pm 20 \mathrm{~g} / \mathrm{Pv}$. They were housed according to the Mexican Regulation (NOM-062-ZOO-1999) which specifies the use of laboratory animals. These rats were organized into three groups with $n=8$ each. The animals were anesthetized with sodium pentobarbital at a dose of $30 \mathrm{mg} / \mathrm{kg}$ to practice a similar wound in depth and length of a $1 \mathrm{~cm}$ on the side of the left leg in the region of the femur involving skin and muscles.

Subsequently, $1 \mathrm{ml}$ of Kombucha extract was topically applied to one of the groups; once a day, for five days. On the second day the early evaluation took place, and on the fifth day the late one. Another groups received approximately $1 \mathrm{~g}$ of a patented healing product which contained antibiotic, anti-inflammatory and vitamins. The last group was checked only physically and left to heal naturally to avoid interference with the results. 


\section{Morphometric and Morphological Analysis}

Tissues of the injured area were formalin-fixed at $10 \%$ and subsequently included in paraffin blocks. They were cut in two series to $5 \mu \mathrm{m}$ and one went to be stained with hematoxylin and eosin of Harris for evaluation of the cell population. The second series was aimed for the Masson trichrome staining technique. Collagen, elastin and keratin were assessed since these elements are the most frequently found in the connective tissue. They work as a support in the formation of new tissue in addition to determining the degree of fibroplasia and angiogenesis which are indicative of the degree of contraction and tissue remodeling elements [13].

\section{Statistical Analysis}

Data were subjected to analysis of variance (ANOVA) for ranges of Kruskal-Wallis and to establish the differences between means the Tukey test, at a significance level of 0.05, the program Sigma Stat 3.1.

\section{Results}

\subsection{Morphometric Analysis}

The number of neutrophils, basophils, eosinophils, lymphocytes, monocytes and fibroblasts were quantified in three groups. The remaining population at this stage such as lymphocytes, eosinophils, basophils and monocytes are not represented in the graphs since there's not a significant difference to be compared against its controls. However, as it was described in morphological analysis.

Based on the average of neutrophils present in the groups, it was determined that there was a significant difference among the groups on the second day (after lesion) when the control group was compared against the patented drug and Kombucha. However, when comparing these two groups they had no significant differences because they had similar averages as shown in Figure 1.

The same thing happened when fibroblasts were quantified against the control group. Figure 2 shows such difference, but not between them.

The results that were obtained on the fifth day stated that there were statistical differences in the average number of neutrophils presented in the repaired tissue while comparing the control group against the Brosin and Kombucha group, but the this didn't happen between these two, although it usually is observed a decrease in cell population at this stage in relation to the previous as shown in Figure 3.

The averages of the number of fibroblasts in this stage were kept the same as in the previous stage while maintaining nearly the same population in all groups and presenting significant differences only when comparing against Brosin and Kombucha, but not between them control Figure 4.

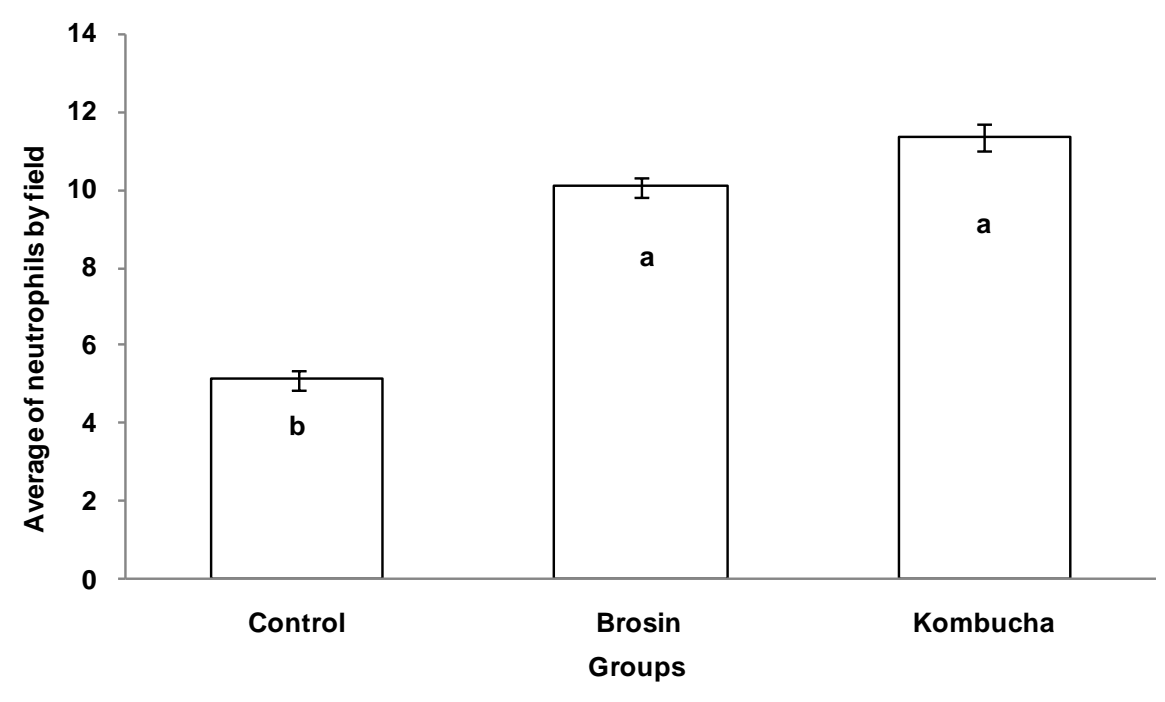

Figure 1. Number of neutrophils by field in cuts of $5 \mu \mathrm{m}$ of the group control, Brosin and Kombucha in the second day postlesion, a, b indicate statistical difference at a level of significance of 0.05, analysis of variance for ranges of Kruskal-Wallis (Sigma Stat 3.1). 


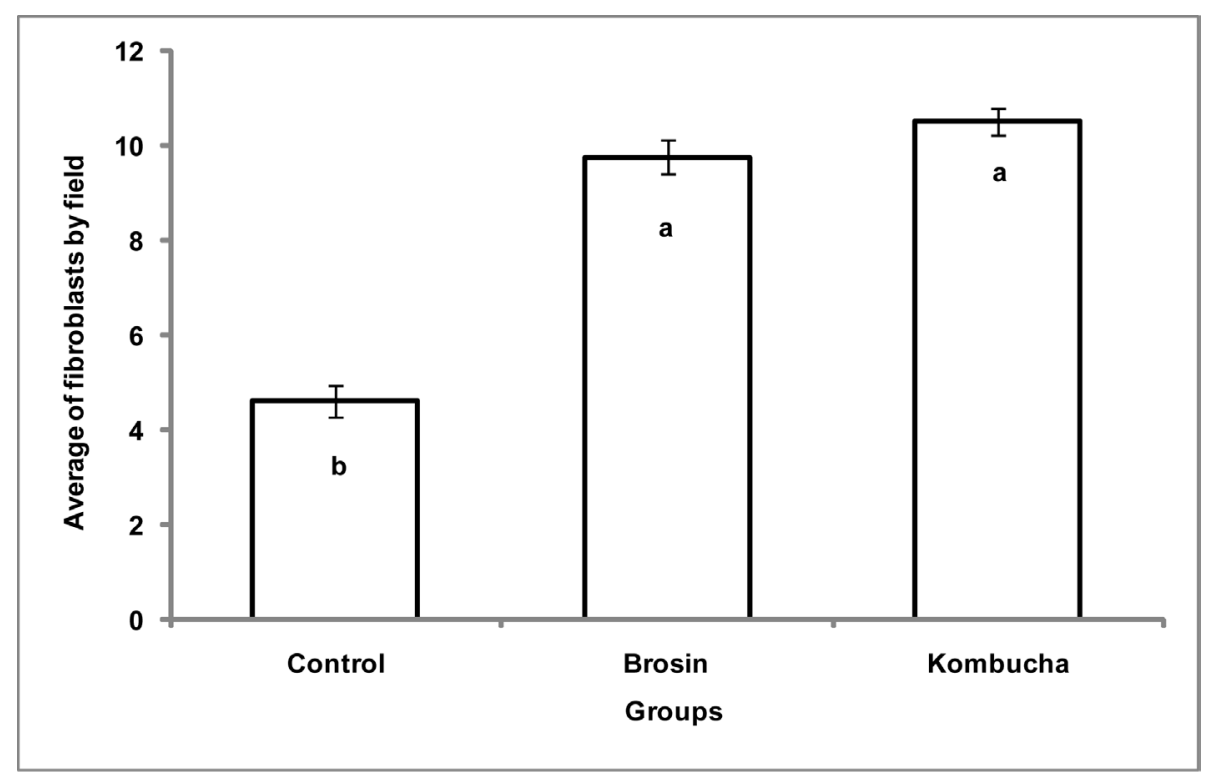

Figure 2. Number of fibroblasts by field in cuts of $5 \mu \mathrm{m}$ in the control groups, Brosin and Kombucha in the second day postlesion, a, b indicate statistical difference at a level of significance of 0.05, analysis of variance for ranges of Kruskal-Wallis (Sigma Stat 3.1).

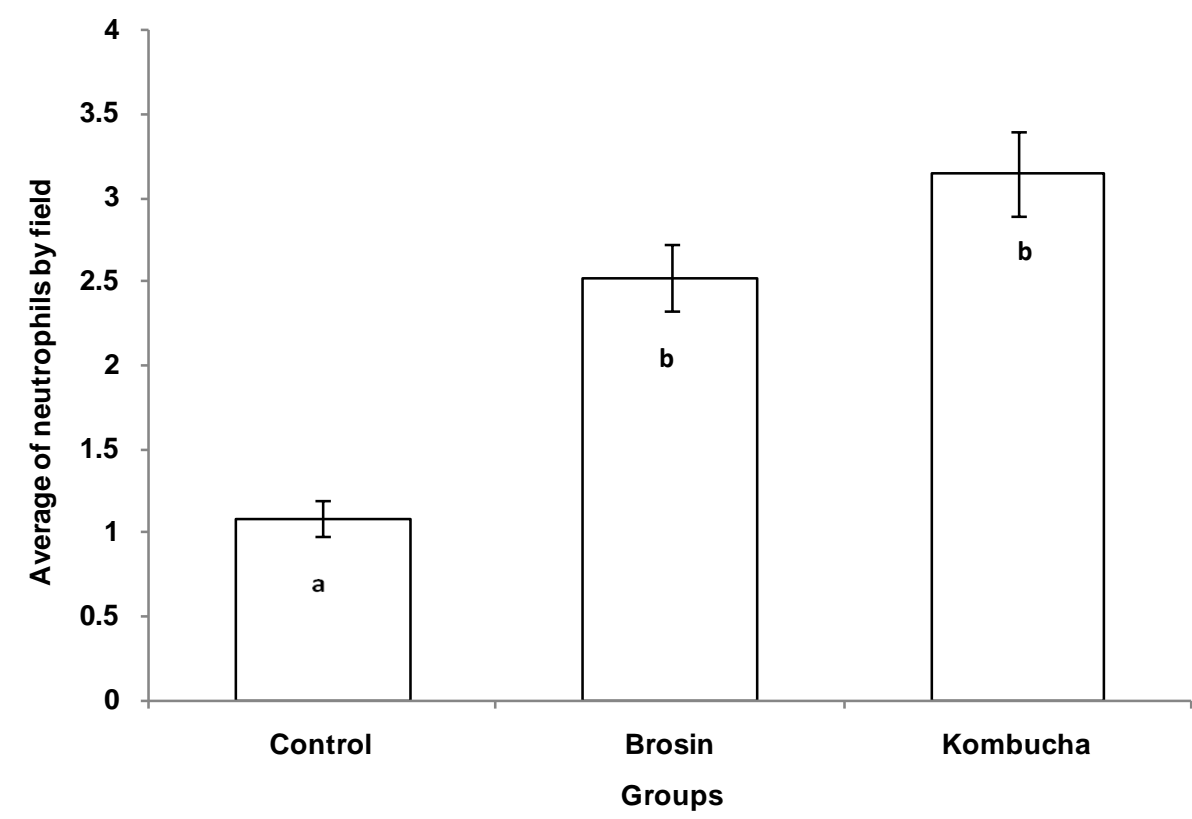

Figure 3. Number of neutrophils by field in cuts of $5 \mu \mathrm{m}$ in the control groups, Brosin and Kombucha fifth day postlesion, a, b indicate statistical difference at a level of significance of 0.05 , analysis of variance for ranges of Kruskal-Wallis (Sigma Stat 3.1).

In this phase, the average of macrophages presented significant statistical differences when the three groups were compared (Figure 5).

\subsection{Morphological Analysis}

The Brosin group, after two days (Figure 6), showed a crust with proliferation of epithelium of the epidermis, thickening and inflammatory cells, edema, detritus, dermal and connective tissue with polymorphic and thin fibers of collagen and elastin, being more dense in the epidermal area. The Kombucha group, on the same period 


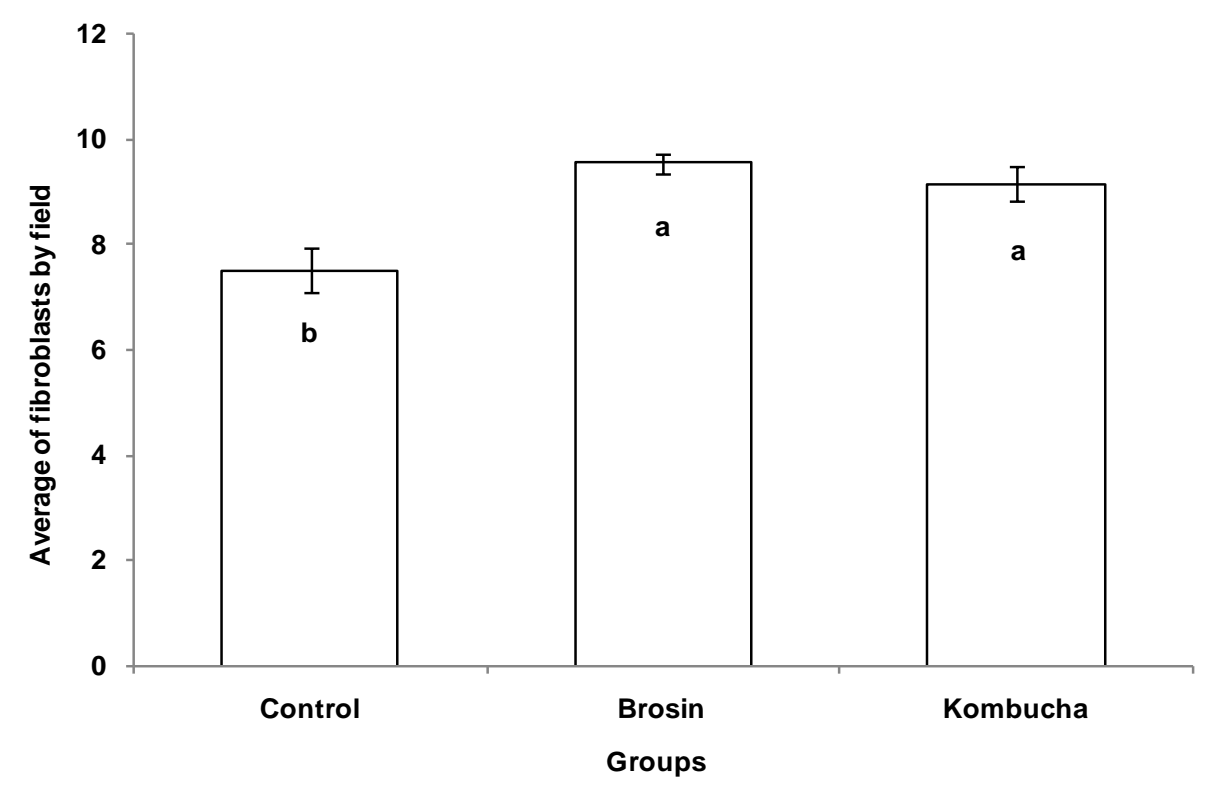

Figure 4. Number of fibroblasts by field in cuts of $5 \mu \mathrm{m}$ in the control groups and experimental, fifth day postlesion a, b indicate statistical difference at a level of significance of 0.05 , analysis of variance for ranges of Kruskal-Wallis (Sigma Stat 3.1).

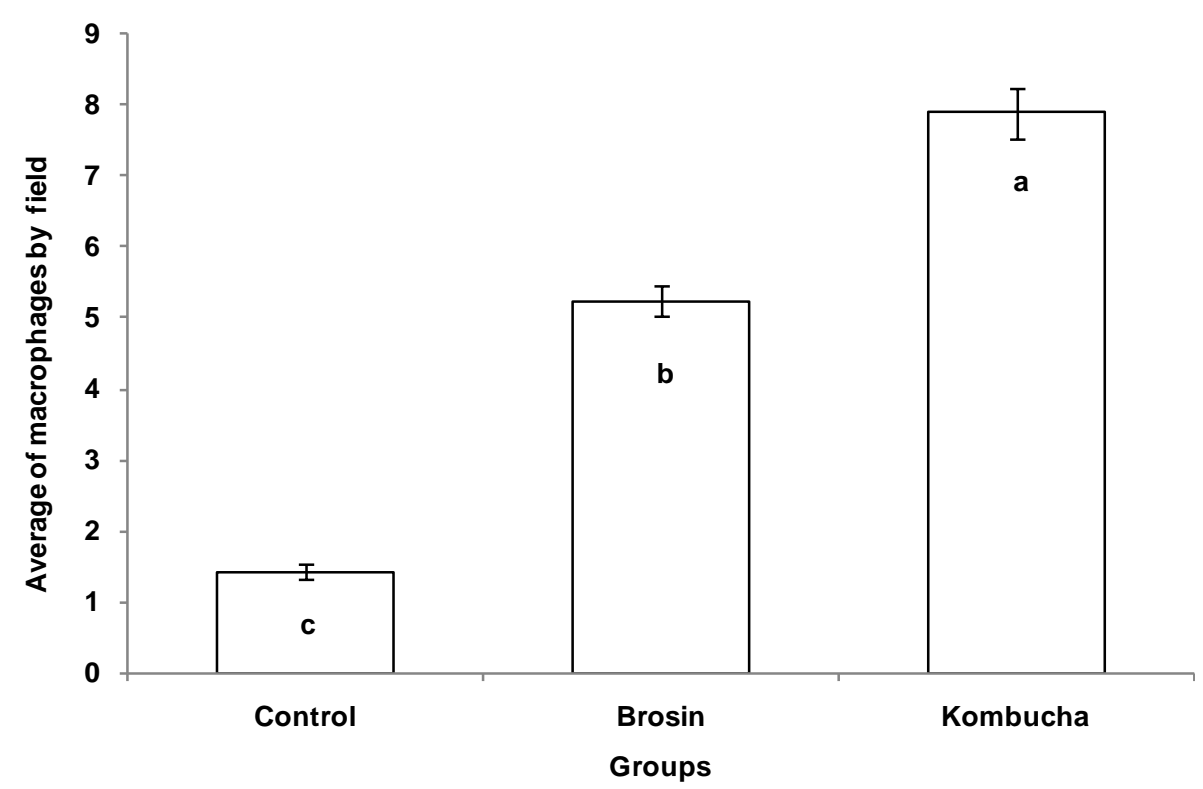

Figure 5. Number of macrophages by field in cuts of $5 \mu \mathrm{m}$ in the control groups and experimental, fifth day postlesion, c, a and b indicate statistical difference at a level of significance of 0.05 , analysis of variance for ranges of Kruskal-Wallis (Sigma Stat 3.1).

of time, shows the most advanced healing process, with the underlying crust to the epithelium of the epidermis which is fused. Its continuity is distinguished a thickening with papillary projections towards the dermis noted difference of the connective scar tissue in the center with the normal connective tissue in the periphery with a pattern polymorphic calangenico thin fibers with jagged edges and a cell population of by fibrocytes, macrophages and erythrocytes, as well as edema circundate is more linear and acidophilic.

Tissues on the second day postlesion of the control group (Figure 6) present an imperfect crust, with moderate proliferation of the underlying epithelium, plenty detritus with inflammatory cells, macrophages primarily fibrous tissue with a pattern scarce colangenico with fibrocytes and fibroblasts in the area more deep dermis 


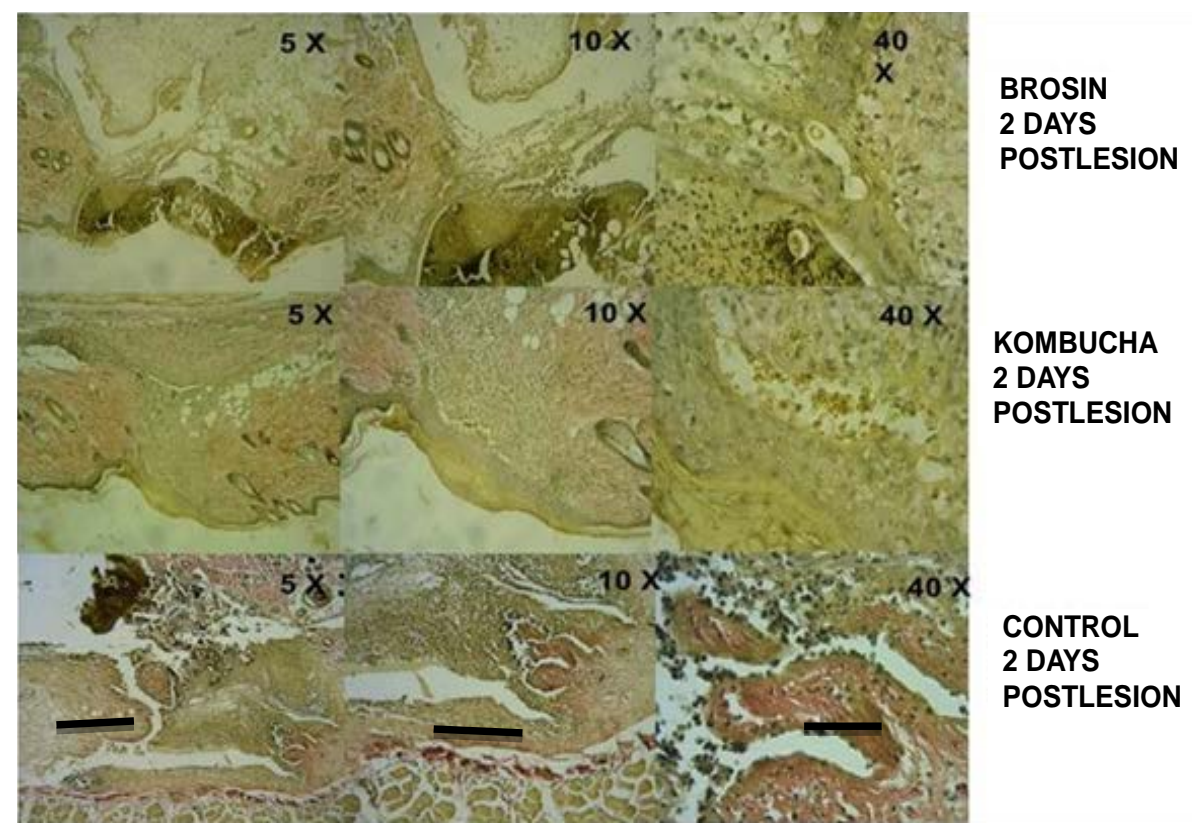

Figure 6. With the $5 \times$ bar $=100 \mu \mathrm{m}, 10$ bar $=40 \mu \mathrm{m} \times$ and $40 \times$ bar $=20 \mu \mathrm{m}$, objectives stained with the technical trichrome are pictures of comparison of cuts of 5 microns of tissue from two days postlesion three groups where the first stage of healing of the skin can be seen and muculo with the formation of the hemostatic plug the presence of a lot of dead cells and the realignment that is happening on their cytoarchitecture of the tissue itself trying to organize the fibers of elastin and collagen that will serve endamiaje and basal array for cell proliferation and the angiogenesis where Kombucha group is observed with a better organization in relation to the other groups.

there are edema and connective tissue is more dense and with focal evidence of circumscribed inflammatory reaction. Tissues of the Brosin group on the second postlesion day (Figure 7) present hyperplasia of the epithelium at the edge of the wound, but with little underlying proliferation to the crust, detritus, severe inflammatory reaction with predominance of neutrophils, neovascularization tendril, fibroplascia with few fibrils of collagen, numerous fibrocytes and fibroblasts inflammatory cells from neutrophils and macrophages of 60/40 ratio. The Kombucha group, on the postlesion day two (Figure 7) already has part of the crust, no epithelial proliferation, detachment although inflammatory reaction is severe and with cell foci nodular type, moderate bleeding, edema and detritus plenty with inflammatory cells from neutrophils and macrophages also of 60/40 ratio. The control group on day two (Figure 7) presents an incomplete crust, aucencia of epitelila, severe inflammatory reaction edema proliferation, detritus cell plenty, neovascularization the proportion of inflammatory cells, neutrophils and macrophages is $20 / 20$.

Morphological of five days postlesion, in the Brosin group (Figure 8) shows severe edema, crust detachment, inflammatory cells are scarce and a connective tissue with thin fibers with plenty fibrocytes and discrete bleeding. Also, the Kombucha group, five days postlesion (Figure 8), shows partial detachment of the crust thickening of the epithelium of the epidermis have glandular and pattern of connective tissue with tendril fibers thickened and moderate cell fibrociticas some erythrocytes and macrophages, discreet edema.

As shown in Figure 8, postlesion day five, the control group presents the crust adhered, epithelial, connective tissue with plenty cells mainly Fibrocytes and fibroblasts proliferation, little fibers of collagen moderate vascular buds and infiltration of macrophages with moderate bleeding. In the tissues of the Brosin group (Figure 9), it is observed little crust, with thickening of the epithelium, papillary projections towards the dermis, normal connective tissue, the scar is more cellularity with some macrophages, fibrocytes fibroblasts and hyperplasia of hair bulbs with discreet edema. On the Kombucha group (Figure 9), it is showed a crust, thickened epithelium presents papillary projections towards the dermis with marked organization collagen, the connective tissue that is normal, the scar is more cellularity with fibrocytes fibroblasts and some macrophages, hyperplasia of hair bulbs with moderate edema. 


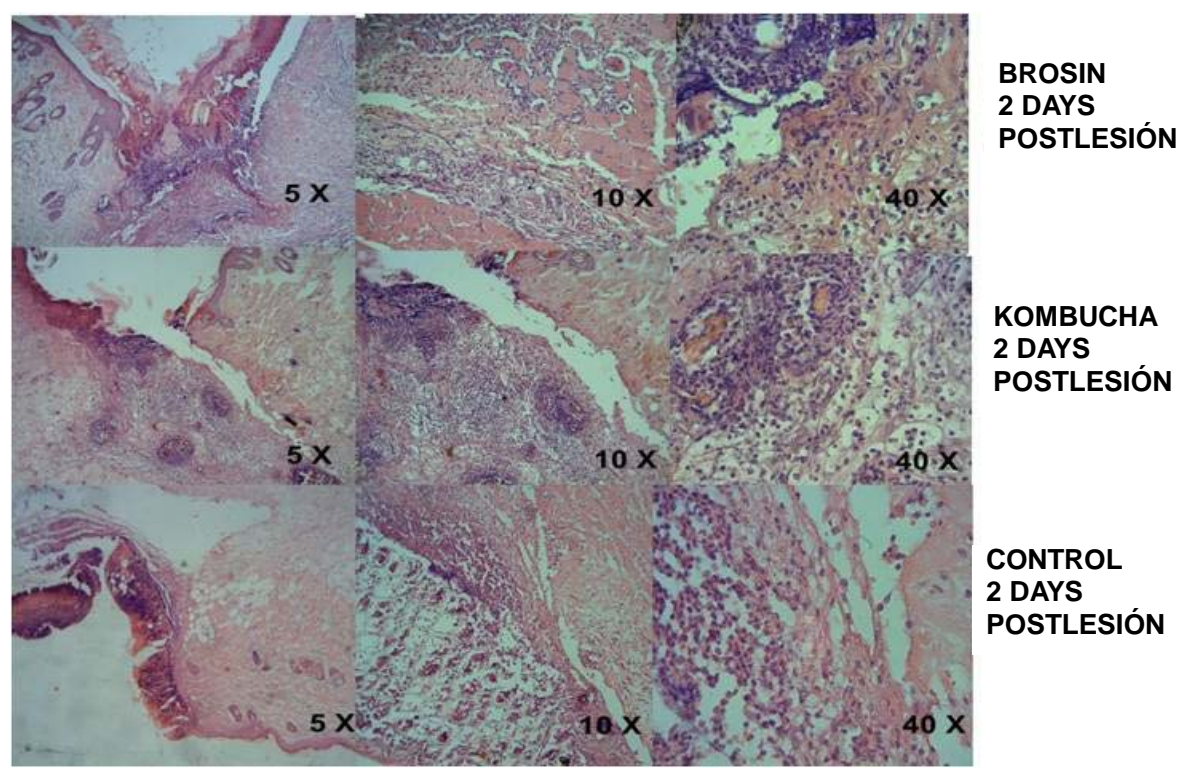

Figure 7. With the $5 \times$ bar $=100 \mu \mathrm{m}, 10$ bar $=40 \mu \mathrm{m} \times$ and $40 \times$ bar $=20 \mu \mathrm{m}$, objectives are pictures of cuts of 5 micron comparison tissue stained with hematoxylin and eosin, two days postlesion of three groups where the first stage of healing the skin and muculo with the formation of the stopper styptic, loss of continuity of the epithelium can be seen a strong inflammatory reaction marked by the presence of a large number of dead cells and cells technique of the inflammation such as neutrophils, macrophages, and fibroblasts.

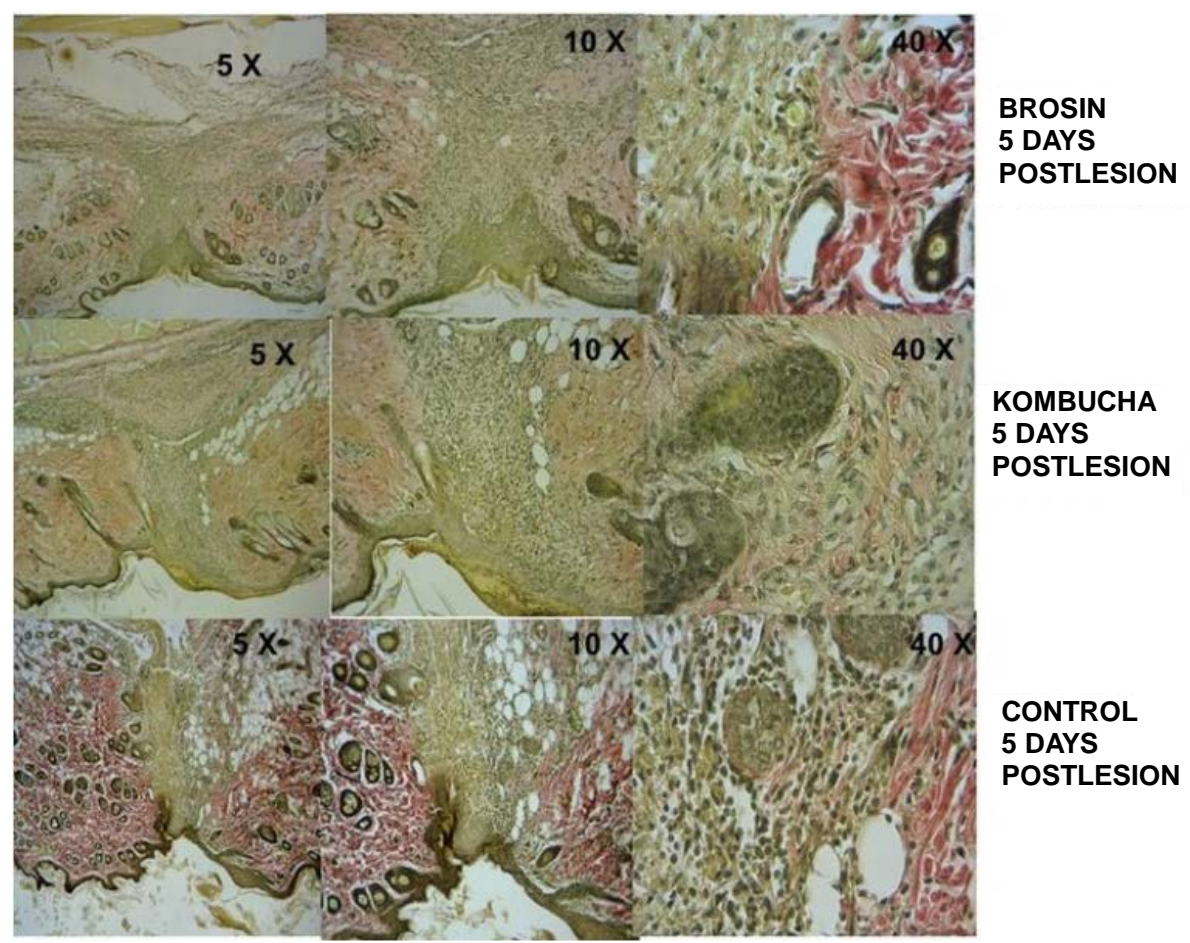

Figure 8. With the $5 \times$ bar $=100 \mu \mathrm{m}, 10$ bar $=40 \mu \mathrm{m} \times$ and $40 \times$ bar $=20 \mu \mathrm{m}$, objectives stained with the technical trichrome are pictures of comparison of cuts of 5 microns of tissue from five days postlesion of three groups where you can see the second and third stage which is proliferation and remodeling of the new tissue can be seen the reconnection of the epithelium, the angiogenesis, hair follicles, the fibers of collagen and elastin and Brosin and Kombucha already present new tissue compaction giving way to the remodelling of the same. 


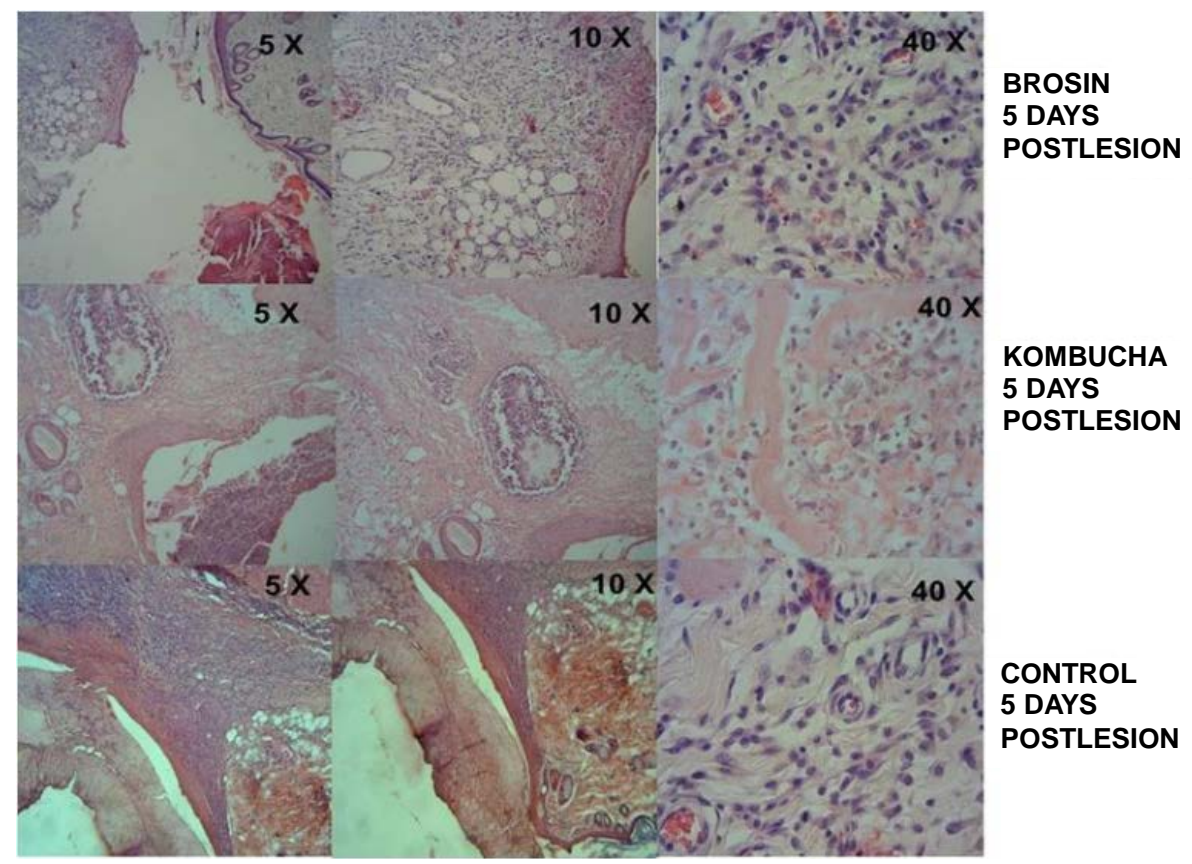

Figure 9. With the $5 \times$ bar $=100 \mu \mathrm{m}, 10$ bar $=40 \mu \mathrm{m} \times$ and $40 \times$ bar $=20 \mu \mathrm{m}$, objectives are pictures of cuts of 5 micron comparison tissue stained with hematoxylin and eosin, two days postlesion of three groups where you can see the stage of proliferation and remodeling of the new tissue technique there are no inflammatory reaction macrophages have removed dead skin cells and fibroblasts and cellular matrix are putting the last touches on the process of repair and remodeling.

The control group (Figure 9) is presented with a discrete crust, thickened epithelium presents papillary projections towards the dermis, there is difference between the connective scar tissue and normal connective tissue in the scar there are more cellularity with some macrophages, fibrocytes fibroblasts and hyperplasia of hair bulbs severe edema.

\section{Discussion}

According to the results in the observed data in graphs and images relating to the early healing we can discuss that actually animals in the control group of two days postlesion, which only has apply them a healing of the wound presented an inflammatory reaction stronger with edema, congestion and moderate cellular proliferation and as a consequence a poor start of the repair of the damaged tissue delaying healing, early and late [14].

Contrary in the group of Brosin and Kombucha is a swelling moderate along with a good cell proliferation and with a major organization in its architecture, the basal array that serves as the substrate is well defined the fibers of collagen and elastin which serve as a bridge for cell migration and remodeling [15].

Images relating to the five days postlesion again looks more delay in the repair process and remodeling of tissue in the group control is thus realized still swelling and lots of dead cells however Kombucha and Brosin groups appreciate good formation of blood vessels already there are reconnection, shrinkage, compaction of connective and epithelial tissue and it is starting with the remodeling [16] [17].

\section{Conclusions}

Based on the results, we can determine that the effect of the Kombucha as a healing skin lesion and muscles to be compared with commercial healing Brosin of Bayer was very good since it was showed that it could decrease the inflammation process quickly, the initiate formation of basal matrix and the cell proliferation continuously at the same time helping the compaction and tissue remodeling without delays or infectious processes in the injured tissue.

A lot of drugs and drugs patent with antibiotic and anti-inflammatory are currently available in the market. 
One of the most common contains neomycin sulfate tetracycline hydrochloride, prednisolone acetate and vitamin $\mathrm{A}$, and offers large effects of repair in the healing process by inhibiting the inflammation and possible contamination; however, this type of medication has a high cost or side effects as containing corticosteroids [5].

Therefore, it is necessary to find and utilize natural and low-cost alternative treatments which are practical and promote effective damaged tissue repair without collateral, economic effects that inhibit inflammation and pollution as it is the case of Kombucha that studies extract prior proved to meet all these qualities [6].

\section{Acknowledgements}

This work was sponsored entirely by the University of Guadalajara, Jalisco, Mexico.

\section{References}

[1] Eming, S.A., Krieg, T. and Davidson, J.M. (2007) Inflammation in Wound Repair: Molecular and Celular Mechanisms. Journal of Investigative Dermatology, 127, 514-521. http://dx.doi.org/10.1038/sj.jid.5700701

[2] Furie, B. and Furie, C. (200) Mechanisms of Thrombus Formation. New England Journal of Medicine, 359, $938-949$. http://dx.doi.org/10.1056/NEJMra0801082

[3] Werner, S. and Grose, R. (2003) Regulation of Wound Healing by Growth Factors and Cytokines. Physiological Reviews, 83, 835-870.

[4] Rozman, P. and Bolta, Z. (2007) Use of Platelet Growth Factors in Treating Wounds and Soft-Tissue Injuries. Acta Dermatovenerologica Alpina, Pannonica et Adriatica, 16, 156-165.

[5] Kanurića, K.G., Hrnjeza, D.V., Ranogajeca, M.I., Milanovića, S.D., Iliĉića, M.D., Vukića, V.R. and Milanović. M. (2011) The Effect of Fermentation Temperature on the Functional Dairy Product Quality. Acta Periodicatechnologica, 42, 63-70. http://dx.doi.org/10.2298/APT1142063K

[6] Cvetkovic, D. and Markov, S. (2002) Cultivation of Tea Fungus on Malt Extract Medium. Acta Periodica Technologica, 33, 117. http://dx.doi.org/10.2298/APT1142063K

[7] Yavari, N., Assadi, M.M., Larijani, K. and Moghadam, M.B. (2010) Response Surface Methodology for Optimization of Glucuronic Acid Production Using Kombucha Layer on Sour Cherry Juice. Australian Journal of Basic and Applied Sciences, 4, 3250-3256.

[8] Sreeramulu, G., Zhu, Y. and Knol, W. (200) Kombucha Fermentation and Its Antimicrobial Activity. Journal of Agricultural and Food Chemistry, 48, 2589-2594. http://dx.doi.org/10.1021/jf991333m

[9] Sreeramulu, G., Zhu, Y. and Knol, W. (2001) Characterization of Antimicrobial Activity in Kombucha Fermentation. Acta Biotechnologica, 21, 49-56. http://dx.doi.org/10.1002/1521-3846(200102)21:1<49::AID-ABIO49>3.0.CO;2-G

[10] Greenwalt, C.-J., Steinkraus, K.-H. and Ledford, R.-A. (200) Kumbucha, the Fermented Tea: Microbiology, Composition, and Claimed Health Effect. Journal of Food Protection, 63, 976-981.

[11] Andrades, P., Sepúlveda, S. and González, J. (2004) Curación avanzada de heridas. Revista Chilena de Cirugía, 56, 396-403.

[12] Rodrígue, M.G.Q., Sotolongo Baró, M.C., Álvarez, R.Q., Corral Salvadó, A. and Batista Veranes, M. (2001) Crema epitelizante de clorofila, carotenos y vitaminas aplicada en heridas abiertas experimentales. Revista Cubana de Medicina Militar, 30, 236-240.

[13] Espino Otero, S., Rodríguez, J.R., Mejías, Y.B., Sierra, O.A., Hijano, I.Q. and Selme, P. (2009) Concordancia clínicoistopatológica en lesiones de cabeza y cuello. MediSur, 7, 25-29.

[14] Veldhoen, M. and Stockinger, B. (2009) TGF $\beta 1$, a ‘Jack of All Trades': The Link with Pro-Inflammatory IL-17-Producing T Cells. Trends in Immunology, 27, 358-361. http://dx.doi.org/10.1016/j.it.2006.06.001

[15] Kwon, Y.B., Kim, H.W., Roh, D.H., Yoon, S.Y., Baek, R.M., Kim, J.Y., Kweon, H.Y., Lee, K.G., Park, Y.H. and Lee, J.H. (2006) Topical Application of Epidermal Growth Factor Accelerates Wound Healing by Myofibroblast Proliferation and Collagen Synthesis in Rat. Journal of Veterinary Science, 7, 105-109. http://dx.doi.org/10.4142/jvs.2006.7.2.105

[16] Valencia Basto, C. (2010) Cicatrización: Proceso de reparación tisular, aproximaciones terapéuticas. Investigaciones Andina, 12, 58-89.

[17] Wang, J.F., Jiao, H., Stewart, T.L., Shankowsky, H.A., Scott, P.G. and Tredget, E.E. (2007) Fibrocytes from Burn Patients Regulate the Activities of Fibroblasts. Wound Repair and Regeneration, 15, 113-121. http://dx.doi.org/10.1111/j.1524-475X.2006.00192.x 